It is not possible to define precisely what contribution is made to the milk activity from the strontium-90 in the soil reservoir, since the charac. teristics of this reservoir, particularly the availability of the activity, are not well known. The contribution from this source clearly becomes more important during periods when the rate of fall-out, and the activity levels in milk, are relatively low. This appears to be reflected at the end of the 1959 open pasture feeding period (Fig. 2) when the activity levels in milk are relatively insensitive to the fall-out rate changes. In our previous report?, we showed that up to 5.5 strontium units in milk sampled at mid-1958 might be derived from the strontium-90 accumulated in the soil up to that. time. The corresponding figure for 1959 is 8.3 strontium units (based on a comparison of cumulative deposition at mid-1959 with that at mid-19581). From this it appears that up to 50 per cent of the rise of strontium-90 in milk between 1958 and 1959 might be ascribed to an increase in the total strontium-90 accumulated on the ground.

As before?, the trend of exsium-137 levels in the milk (Fig. 1c) is essentially parallel to that for strontium-90, although there is some indication that the fall in cæsium-137 levels after May 1959 is significantly steeper than that for strontium-90. The cæsium-137 ( $\mu \mu c . / 1$.)/strontium-90 ( $\mu \mu \mathrm{c} . / 1$.$) ratio for$ May-August $1959,8 \cdot 6$, is somewhat lower than the corresponding ratio, 10.0 , for the same period of 1958. At the end of 1959 the ratio has decreased further (average for September-November $1959=$ $6 \cdot 5$, December $=3 \cdot 1$ ). These results suggest that in the case of cxsium-137 the fraction of milk activity derived from the soil reservoir may be relatively less important than in the case of strontium-90. It may be noted that the cæsium-137 level in the milk at December 1959 (30 $\mu \mu \mathrm{c} . / \mathrm{gm}$. potassium) is the lowest value yet recorded in our Felinfach series, which covers samples collected during 1956-59 (max. value $=160 \mu \mu \mathrm{c} . \mathrm{gm}$. potassium, at May 1959).

The significance of the arguments presented above lies in their bearing on the prognosis of the future trend of fission product levels in milk. Assuming that there is no large-scale resumption of weapons testing, and that the 1960 rainfall will be near (or less than) average, an estimate based on current theory ${ }^{3}$ of fall-out mechanisms suggests that the average rate of strontium-90 fall-out during March-August 1960 will be somewhat less than half that during the same period of 1959. Similarly, the total strontium-90 accumulated on the ground in the Felinfach-Carmarthen region at mid-1960 would not be expected to rise to more than $1 \cdot 2$ times the value at mid-1959. On this basis, the figure noted above $(8 \cdot 3$ strontium units) as the mid-1959 upper limit for milk activity derived from the total soil reservoir becomes $10 \cdot 0$ strontium units at mid-1960. Likewise, the component which depends on the rate of fall-out is expected to be less than $0.5 \times(21 \cdot 4-8 \cdot 3)$ strontium units $=6 \cdot 6$ strontium units at mid-1960. This treatment suggests that the mid-1960 strontium-90 level in mills from this region will be less than $16 \cdot 6$ strontium units, that is, less than three quarters of the mid-1959 value. The corresponding figure for cæsium-137, based on the cæsium-137/strontium-90 ratio $(6 \cdot 5)$ at the end of the open pasture feeding period of 1959 , is $80 \mu \mu \mathrm{c} . / \mathrm{gm}$. potassium.

It should be noted that the figures presented above refer to levels in milk from a single region and they should not be taken to represent the average values for Britain as a whole. The trend of the strontium-90 levels is, however, broadly consistent with the country-wide picture so far described". In view of the outstanding importance of the contribution from milk to the levels of activity which occur in human bone, the above prediction of a downward trend in milk activity suggests that the future trend of strontium-90 levels in newly formed bone should also be downward.

We are indebted to Prof. W. V. Mayneord, in whose Department the work was carried out, for his constant guidance and encouragement.

${ }^{1}$ Crooks, R. N., Osmond, R. G. D., Owers, M. J., and Fisher, E. M. R., Atomic Bnergy Research Establishment, Harwell, $R 3094$ (1959),

2 Peirson, D. H., Crooks, R. N., and Fisher, E. M. R., Nature, 186, 224 (1960).

${ }^{3}$ Anderson, W., Bentley, R. E., Burton, L. K., Crookall, J. O., and Greatorex, C. A., Nature (in the press).

" "Strontium-90 in Milk and Agricultural Materials in the United Kingdom 1958-1959", Agricultural Research Councll (H.M. Stationery Office, London, 1960).

${ }^{5}$ Arden, J. W., Bryant, F. J., Henderson, E. H., Lloyd, G. D., and Morton, A. G., Atomic Energy Research Establishment, Harwell, $R 3246(1960)$

Mayneord, W. V., Anderson, W., Bentley, R. E., Burton, I. K., Crookall, J. O., and Trott, N."G., Nature, 182, 1473 (1958).

${ }^{7}$ Anderson, W., Burton, L. K., and Crookall, J. O., Nature, 184, 89 (1959).

\title{
OBITUARIES
}

\section{Prof. John F. Fulton}

Prof. John F. Fulton, who died on May 29, was the son of John Farquhar and Edith Stanley Fulton, and was born at St. Paul, Minnesota, on November 1, 1899, going later to Harvard and graduating there as M.S. in 1921. He was selected as a Rhodes Scholar and had the good fortune to be accepted by Magdalen College, Oxford, where he graduated B.A. with firstclass honours in 1923, being in the same group as Howard Florey, later to become internationally well known for his work on penicillin. Fulton, at about this time, was extremely good-looking, as a photograph taken in 1932 shows. Ho became a University demonstrator in physiology under Sir Charles Sherrington, and in 1925 had already reached his twenty-seventh publication in journals. Sir William Osler had died in 1919 , but the very wonderful Lady Osler still regarded her home at 13 Norham Gardens, Oxford, as a centro for the young, and she and Lady "Sherrie" were two on whom one never failed to call, usually on Sundays at tea-time, every term. Fulton helped to catalogue "Bibliotheca Osleriana", which was finally published in 1929; but before that, with the M.A. and D.Phil. Oxon. to his credit, he returned for a while to Harvard, where he took his M.D. in 1927. As assistant neurological surgeon at the Peter Bent Brigham Hospital, he worked under the master neuro-surgeon, Harvoy Cushing, and he became in succession his pupil, close friend and, later, biographer.

As a Fellow of Magdalen he continued research in neurophysiology during 1928-30, and then in 1931 
he was appointed to the Sterling chair of physiology at Yale, where one of his first decisions was to name his new home the 'Laboratory' rather than the 'Department' of Physiology. Many came to him from outside, attracted, as The Times obituary notice of him stated, by his breadth of outlook, humanistic approach, and personal example, his own interests being mainly electrophysiological, electro-cardiographic, and endocrinological, with the physiology of aviation becoming an outstanding fourth during the Second World War.

In Oxford he had married Lucia Pickering Wheatland, and in 1956 there was a reception in the History of Medicine Library at Yale to mark his total of twenty-five years of service in the Laboratory of Physiology and in the Department of the History of Medicine. Fulton was given a bound copy of a special issue of the Yale Journal of Biology and Medicine, and a silver medal which his friends had inscribed to him as physiologist, teacher and humanist.

In 1959, on his sixtieth birthday, friends met again, this time at his home at Mill Rock, to be presented with copies of "The Making of a Library", in the letters on which it was based being one from Arnold C. Klebs which quoted :

"Grau ist alle Theorie

Und grün der goldne Baum des Lebens",

and in which he stated that he believed in loving the old authors when they had something lovable. Wilmarth S. Lewis briefly said that Dr. Fulton alone survived of the three friends (Harvey Cushing, Klebs and Fulton) who brought the Historical Library to Yale, and that November 1, 1959, was a moment of congratulation and thankfulness: of thankfulness for Fulton's restored health, and of congratulation on his being only sixty, with years more of discovery and instruction before him. Elizabeth Thomson, who with Madeline Stanton was responsible for most of the planning of the reception, wrote to me that Mrs. Fulton was meeting guests at the top of the steps looking lovely and giving no hint of the strain of arranging a party of seventy sub rosa. However, Fulton found everything a real surprise and he was simply delighted with the book.

For myself I am indebted to him for countless kindnesses over the years, including the period after the First World War, and I am truly sorry that I am not to greet him in person at the tercentenary of the Royal Society, and at the centenary of the National Hospitals for Nervous Diseases. Ho would, I know, have entered with zest into both occasions.

KenNeth J. FrankLin

\section{Dr. S. F. Birch}

Stanley Francis Birch was born in November 1899 at Pewsey in Wiltshire, and was educated at Hurstpierpoint College and St. Paul's School, before going to the Imperial College of Science and Technology, whence he graduated. Working with Prof. J. F. Thorpe, he obtained the degree of doctor of philosophy for research work on three-carbon tautomerism, after which he joined the staff of the (then) Anglo Persian Oil Company, with which he was to spend the whole of his working life.

His great interest was in research connected with organic chemistry, and it was in this sphere that, in 1923, he commenced his career. Under Dr. A. E. Dunstan and with a small band of scientists, he worked in a country house at Sunbury-on-Thames; these premises he was to see develop into the Research Centre of the British Petroleum Co., Ltd. An investigation of the malodorous components of the lighter fractions from Persian crude oils led to the identification of mercaptans and from this discovery stemmed a major research effort, concerning the nature and properties of sulphur compounds in petroleum, which he continued, with some interruptions, for the next thirty-five years. In this field he was regarded as an authority, and he published numerous scientific papers and gave many lectures both in Britain and the United States. He visited the latter country many times and was well known in many industrial research centres, universities and organizations connected with the American Petroleum Institute and American Chemical Society, of which he was a member.

The study of the reactions of hydrocarbons was, however, a branch of chemistry in which he made signal contributions to the petroleum industry. This work had, as its major achievement, the discovery of the sulphuric acid alkylation process in 1936 which, together with processes resulting from the determination of the octane numbers of pure hydrocarbons, and studies of the fractionation of petroleum distillates, formed the basis of the supply, by the Abadan refinery, of vast quantities of aviation spirit during the Second World War. His researches connected with the reactions of hydrocarbons made him realize, from a very early date, the potentialities of the petroleum chemical industry, and at his death on March 25 he held the position of research associate in the Petroleum Chemicals Department.

Birch believed very strongly that research could only be directed by those in close contact with the practical operations and that most discoveries came about as a result of critical observation and experimental skill. Until the last three years of his career, when administrative duties forced him, reluctantly, to move, he occupied an office situated close to the laboratories and was a frequent visitor to the bench where many informal technical discussions took place. 'Bill', as he was known to his friends, had wide-ranging interests apart from his research work. He was keenly interested in the theatre and ballet and antique works of art, and many of his leisure hours were spent building electronic and other gadgets.

$\mathrm{H}_{e}$ died on March 25, and is survived by his wife, Hilda Mary, whom he married on June 24, 1925. His many friends will sadly miss the pleasure of his company and the stimulation of his personelity.

\section{R. A. DEan}

\section{Dr. J. H. Oliver}

ON June 1 James Herbert Oliver died suddenly in Ankara. He had undertaken a visit to Ceylon and India and was returning to Britain by way of Turkey, where, in pursuance of a life-long interest, he was proposing to study native barleys.

Born in Portsmouth in 1901, he was educated at St. John's College, Southsea, and the Municipal College, Portsmouth, and after a period of private study he graduated in 1920. His first post was at the Olympia Agricultural Research Station near Leamington, where he worked under Dr. Herbert Hunter, who was widely known for the production of the brewers' barleys, Spratt Archer and Plumage Archer. It was here that Oliver developed the interest that he followed so assiduously throughout 